\title{
Wogonin inhibits the proliferation of myelodysplastic syndrome cells through the induction of cell cycle arrest and apoptosis
}

\author{
HUIXIA LU ${ }^{1}$, FENG GAO $^{2}$, GUOFANG SHU ${ }^{1}$, GUOHUA XIA $^{2}$, ZEYE SHAO $^{2}$, \\ HANGQIN LU ${ }^{2}$ and KEPING CHENG ${ }^{1}$ \\ ${ }^{1}$ Department of Clinical Laboratory Medicine of Zhongda Hospital, School of Medicine; ${ }^{2}$ Department of \\ Laboratory Medicine of Medical School, Southeast University, Nanjing, Jiangsu 210009, P.R. China
}

Received January 24, 2015; Accepted September 1, 2015

DOI: $10.3892 / \mathrm{mmr} .2015 .4353$

\begin{abstract}
The present study aimed to assess the effects of the flavonoid, wogonin, and its underlying mechanism on myelodysplastic syndrome (MDS) in SKM-1 cells. In the present study, wogonin inhibited the cell proliferation of SKM-1 cells in a dose- and time-dependent manner, with the concentration required to yield a half maximal inhibitory concentration $\left(\mathrm{IC}_{50}\right)$ of $212.1 \mu \mathrm{mol} / 1$ at $24 \mathrm{~h}$, and $43.4 \mu \mathrm{mol} / 1$ at $72 \mathrm{~h}$. Furthermore, wogonin induced cell cycle arrest at the $\mathrm{G}_{0} / \mathrm{G}_{1}$ phase and induced the apoptosis of the SKM-1 cells, which possibly accounted for the antiproliferative effects of wogonin. Notably, the data in the present study revealed that wogonin upregulated the expression of $\mathrm{p} 21^{\mathrm{Cip} 1}$ and $\mathrm{p} 27^{\mathrm{Kip} 1}$, and downregulated the expression of cyclin D1 and cyclin-dependent kinase 4 , causing a $G_{0} / G_{1}$ phase arrest, halting cell cycle progression, and inducing apoptosis in the MDS cells, which was mediated by the mitochondrial pathway through a modulation of the ratio of Bcl-2 to Bax. Therefore, the present study suggests that wogonin may be a logical therapeutic target in the treatment of MDS.
\end{abstract}

\section{Introduction}

Myelodysplastic syndrome (MDS) comprises a heterogenous group of acquired bone marrow disorders, which is characterized by the dysplastic growth of hematopoietic stem cells. MDS typically exerts its effects in multiple cell lines and has a propensity to progress to acute myelogenous leukemia. Although hematopoietic stem cell transplantation represents the only mode of treatment with curative potential, the relatively high morbidity and mortality of this approach limits its usefulness $(1,2)$. Therefore, effective agents with more benign toxicity profiles are urgently required for the treatment of this disease.

Correspondence to: Miss Huixia Lu, Department of Clinical Laboratory Medicine of Zhongda Hospital, School of Medicine, Southeast University, 87 Dingjiaqiao, Gulou, Nanjing, Jiangsu 210009, P.R. China

E-mail:nj-lhx@163.com

Key words: SKM-1 cells, myelodysplastic syndrome, wogonin, apoptosis, cell cycle
At present, the search for novel antitumor substances obtained from plants is intensifying. Wogonin (5,7-dihydroxy-8-methoxy-flavone), a flavonoid from the root of the medicinal herb Scutellaria baicalensis Georgi, has been recognized as a potent anticancer agent due to its broad toxicity to various types of tumor cell lines (3-7). Notably, at doses which are lethal to tumor cells, wogonin revealed no, or little, toxicity for normal cells and exhibited no evident toxicity in animals $(4,6,8)$. The molecular mechanisms underlying these growth-suppressive effects are considered to include changes in the oxidation/reduction status, cell cycle inhibition (9), induction of apoptosis (8) and phosphorylation of the vascular endothelial growth factor receptor 2 (VEGFR-2) (10). However, the underlying molecular mechanism of its anticancer activity remains to be fully elucidated.

Apoptosis, or programmed cell death, is critical for the normal development, function and homeostasis of multicellular organisms. Apoptosis is considered as a process which may be exploited for the removal of precancerous and cancerous cells (11), and reduced levels of apoptosis are considered to be a fundamental component in the pathogenesis of cancer. Therefore, further development of agents which are able to induce, or enhance, the extent of apoptosis may provide a promising strategy for enhancing the anticancer potential of several anticancer drugs (12). An accumulating body of evidence supports that cell cycle arrest and apoptosis are closely associated with cell proliferation in mammalian cells $(9,13)$. It is well known that the transition from one cell cycle phase to another occurs in an orderly fashion, and cell cycle control is the major regulatory mechanism underlying cell growth, which is regulated by cyclin-dependent kinases (CDKs) and their cyclin partners $(14,15)$. Although the effects of wogonin on antiproliferative and apoptotic activity have been documented in various human cancer cells, its therapeutic efficacy and the underlying mechanisms in MDS remain to be elucidated. The present study aimed to investigate the potency of wogonin and to assess the signaling pathways involved in modulating apoptosis in MDS cells.

\section{Materials and methods}

Reagents. Wogonin (purity $>98 \%$; Jiangsu Key Lab of Carcinogenesis and Intervention, China Pharmaceutical 
University, Nanjing, China) was dissolved in dimethyl sulfoxide (DMSO; Sigma-Aldrich, St. Louis, MO, USA), and the final concentration of DMSO was $>0.15 \%$, which exhibited no toxicity to the SKM-1 cells. The 3-(4,5-dimethylthiazol-2-yl)-2,5-diphenyltetrazolium bromide (MTT) reagent was supplied by Sigma-Aldrich, the annexin V-fluorescein isothiocyanate (FITC) apoptosis detection and cell cycle detection kits were obtained from BD Biosciences (Franklin Lakes, NJ, USA), 4',6-diamidino-2-phenylindole (DAPI) was purchased from Beyotime Institute of Biotechnology (Haimen, China), the bicinchoninic acid (BCA) protein assay kit was from Biosynthesis Biotechnology Co., Ltd. (Beijing, China) and monoclonal antibodies, including rabbit antihuman CDK4 (cat. no. 12790), rabbit antihuman cyclin D1 (cat. no. 2978), mouse antihuman $\mathrm{p} 21^{\mathrm{Cip} 1}$ (cat. no. 2946), rabbit antihuman p27 ${ }^{\text {Kip1 }}$ (cat. no. 3688), rabbit antihuman Bax (cat. no. 5023), rabbit antihuman Bcl-2 (cat. no. 4223), rabbit antihuman poly(ADP-ribose) polymerase (PARP) (cat. no. 9532), rabbit antihuman cleaved (c)-PARP (cat. no. 5625), rabbit antihuman cytochrome $c$ (cat. no. 11940), rabbit antihuman caspase-3 (cat. no. 14220), mouse antihuman caspase-9 (cat. no. 9508) and mouse antihuman $\beta$-actin (cat. no. 3700), were supplied by Cell Signaling Technology, Inc. (Danvers, MA, USA).

Cell line and cell culture. SKM-1, an MDS cell line, was obtained from the Japanese Collection of Research Bioresources Cell Bank (Osaka, Japan) (16). The cells were cultured in RPMI-1640 medium (Gibco Life Technologies, Carlsbad, CA, USA) containing $10 \%$ fetal bovine serum (Gibco Life Technologies), $100 \mathrm{U} / \mathrm{ml}$ penicillin (Sigma-Aldrich, St. Louis, MO, USA) and $100 \mu \mathrm{g} / \mathrm{ml}$ streptomycin (Sigma-Aldrich) in an environment of saturated humidity, $5 \% \mathrm{CO}_{2}$ at $37^{\circ} \mathrm{C}$. Cells in the logarithmic growth phase were used in all experiments.

Measurement of cell growth and viability. The SKM-1 cells were seeded at a density of $5 \times 10^{3}$ cells/well into 6 -well plates and were allowed to grow overnight. Subsequently, the cells were treated with $20,40,80,120$ or $160 \mu \mathrm{mol} / \mathrm{l}$ wogonin, whereas only RPMI-1640 medium was added for the control group. Following incubation for 12, 24, 48 or $72 \mathrm{~h}$, an MTT assay was performed to measure the cell viability, as described previously (17), and the absorbance at $570 \mathrm{~nm}$ was recorded using a Model 550 microplate reader (Bio-Rad Laboratories, Tokyo, Japan).

Cell morphological assessment. Following culture as described above, the SKM-1 cells were collected and spread onto the slides. Subsequently, the cells were fixed with ice-cold 4\% paraformaldehyde for $20 \mathrm{~min}$, permeabilized with $0.1 \%$ Triton X-100 for 25 min and washed with ice-cold phosphate-buffered saline (PBS), followed by staining with DAPI $(1 \mu \mathrm{g} / \mathrm{ml})$ for $25 \mathrm{~min}$ at $4^{\circ} \mathrm{C}$ in the dark. Morphological changes of the nuclei of cells were undergoing apoptosis (100 cells) were recorded at the reference points using a phase-contrast microscope (Olympus CKx41; Olympus, London, UK).

Apoptosis assay by flow cytometric analysis (FCM). Cell apoptosis was identified by FCM using annexin V/propidium iodide (PI) staining, as described previously (17). Briefly, the SKM-1 cells $\left(1 \times 10^{5}\right.$ cells $)$ were treated and incubated, as described in the previous section. The cells were subsequently collected by centrifugation at $920 \mathrm{x}$ g for $5 \mathrm{~min}$, and washed once in ice-cold PBS, prior to the assessment of apoptotic cell death using a FACSCalibur flow cytometer (BD Biosciences, San Jose, CA USA), according to the manufacturer's instructions.

Cell cycle distribution. The SKM- 1 cells $\left(1 \times 10^{5}\right.$ cells/well $)$ were seeded into a 6 -well plate for $24 \mathrm{~h}$ at $37^{\circ} \mathrm{C}$. The cells were washed once with PBS, the medium was replaced with fresh medium, and the cells were subsequently treated with various concentrations of wogonin. Following treatments for the various durations, the cells were collected, fixed with $70 \%$ ethanol, incubated with $25 \mu \mathrm{g} / \mathrm{ml}$ ribonuclease A and stained with $50 \mu \mathrm{g} / \mathrm{ml}$ PI for $30 \mathrm{~min}$ at room temperature in the dark. Subsequently, the cell cycle data were calculated by FCM (BD Biosciences), according to the manufacturer's instructions.

Western blot analysis. Western blotting was performed, as described previously $(17,18)$. Briefly, the total protein was isolated from the harvested cells and the quantity of protein was measured using a BCA protein assay. Samples containing $25 \mu \mathrm{g}$ protein were separated using $10 \%$ sodium dodecyl sulfate-polyacrylamide gel electrophoresis and transferred onto a nitrocellulose membrane (Bio-Rad Laboratories, Inc. Hercules, CA, USA). Non-specific binding sites were blocked for $1 \mathrm{~h}$ with $5 \%$ non-fat milk, prior to an incubation with the following primary antibodies diluted in PBS at $4^{\circ} \mathrm{C}$ overnight: Anti-CDK4 (1:1,000), anti-cyclin D1 (1:1,000), anti-p21 $1^{\text {Cip1 }}$ $(1: 1,000)$, anti-p2 $7^{\mathrm{Kip} 1}(1: 1,000)$, anti-cytochrome $c(1: 1,000)$, anti-caspase-9 (1:1,000), anti-caspase-3 $(1: 1,000)$, anti-PARP $(1: 1,000)$, anti-c-PARP $(1: 1,000)$, anti-Bcl-2 $(1: 1,000)$, anti-Bax $(1: 1,000)$, and anti- $\beta$-actin $(1: 1,000)$ Subsequently, a secondary horseradish peroxidase-conjugated goat anti-mouse antibody (1:1,000; Santa Cruz Biotechnology, Inc.) was added for $1 \mathrm{~h}$ at room temperature. The blots were visualized using an enhanced chemiluminescence system (Amersham, Buckinghamshire, UK), and the density of $\beta$-actin served as an internal loading control.

Statistical analysis. All data are expressed as the mean \pm standard deviation for experiments performed in triplicate, and the data were analyzed using the Statistical Package for Social Science (SPPS version 13.0; SPSS, Inc., Chicago, IL, USA). Statistically significant differences between the experimental groups were determined using Student's t-test. $\mathrm{P}<0.05$ was considered to indicate a statistically significant difference.

\section{Results}

Inhibition of cell proliferation. Following incubation with different concentrations of wogonin for the various durations, the proliferation of the SKM-1 cells was markedly inhibited (Fig. 1). Significant differences were observed between the different groups $(\mathrm{P}<0.05)$, and the concentration of wogonin required to yield a half maximal inhibitory concentration $\left(\mathrm{IC}_{50}\right)$ of the proliferation, as measured at the 24,48 and $72 \mathrm{~h}$ time points, was $212.1,58.0$ and $43.4 \mu \mathrm{mol} / 1$, respectively. Therefore, these results demonstrated that wogonin markedly 
inhibited the proliferation of SKM-1 cells in a time- and dose-dependent manner.

Cell morphological assessment following treatment with wogonin. The morphological changes due to apoptosis occurring in the nuclei of the cells were observed under a fluorescence microscope. The untreated SKM-1 cells exhibited a pale blue fluorescence, demonstrating an even pattern of distribution of the chromatin in the nucleolus (Fig. 2A), whereas those treated with wogonin exhibited a dose-associated increase in the fraction of apoptotic cells with condensed and fragmented DNA, as revealed by the darker blue fluorescence compared with that in the non-apoptotic cells (Fig. 2B and $\mathrm{C}$ ), suggesting that wogonin induced cell apoptosis in a dose-dependent manner.

Wogonin treatment induces cell apoptosis. The apoptotic cells were further quantified using the annexin V/PI double-staining assay. Following treatment with various concentrations of wogonin for $24 \mathrm{~h}$, the total percentages of cells in an apoptotic state, as calculated by the sum of those cells undergoing early and late apoptosis, are shown in Fig. 3A and B. These results indicated that wogonin induced apoptosis in the SKM-1 cells in a dose-dependent manner. Furthermore, when the SKM-1 cells were incubated with $40 \mu \mathrm{mol} / 1$ wogonin for 12,24 and $48 \mathrm{~h}$, the apoptotic rate increased significantly with the duration of the experiment $(\mathrm{P}<0.05$; Fig. $3 \mathrm{C})$. These data provided evidence that apoptosis was induced in the wogonin-treated SKM-1 cells.

Wogonin treatment causes $G_{0} / G_{1}$ phase arrest in the SKM-1 cells. Following treatment with wogonin for $24 \mathrm{~h}$, the percentages of SKM-1 cells in the $\mathrm{G}_{0} / \mathrm{G}_{1}$ phase increased from $38.96 \pm 2.62 \%$ in the untreated cells, to $51.53 \pm 2.76,63.68 \pm 2.82$ and $76.52 \pm 3.46 \%$ in the cells treated with increasing concentrations of wogonin (40, 80 and $120 \mu \mathrm{mol} / 1$, respectively; Fig. 4A and B). Furthermore, the number of SKM-1 cells in the $\mathrm{S}$ and $\mathrm{G}_{2} /$ mitosis phases correspondingly decreased. Therefore, these results indicated that wogonin induced a $G_{0} / G_{1}$ cell-cycle arrest in a dose-and time-dependent manner.

Expression of cell cycle proteins following treatment with wogonin. Following treatment with increasing concentrations of wogonin $(40,80$ and $120 \mu \mathrm{mol} / \mathrm{l})$ for $48 \mathrm{~h}$, the levels of cyclin D1 and its upstream kinase, CDK4, in the SKM-1 cells were reduced in a dose-dependent manner (Fig. 5). By contrast, a marked increase in the protein expression levels of p2 $1^{\text {Cip1 }}$ and $\mathrm{p} 27^{\mathrm{Kip} 1}$ were observed in the SKM-1 cells following treatment with the identical doses of wogonin for $48 \mathrm{~h}$ (Fig. 5). Taken together, these data indicated that wogonin also exerts a growth-inhibitory effect on the cells by inducing cell cycle arrest at the $G_{1} / S$ phase transition, followed by the upregulation of the expression of $\mathrm{p} 21^{\mathrm{Cip} 1}$ and $\mathrm{p} 27^{\mathrm{Kip} 1}$, and the downregulation of the expression of cyclin D1 and CDK4 in the SKM-1 cells.

Expression of apoptosis-associated proteins following treatment with wogonin. Following treatment for $48 \mathrm{~h}$, wogonin increased the expression levels of the proapoptotic proteins Bax, activated caspases 3 and 9, and activated c-PARP in the SKM-1 cells, whereas it caused a decrease in the expression of the antiapoptotic protein, Bcl-2, and of the inactive form

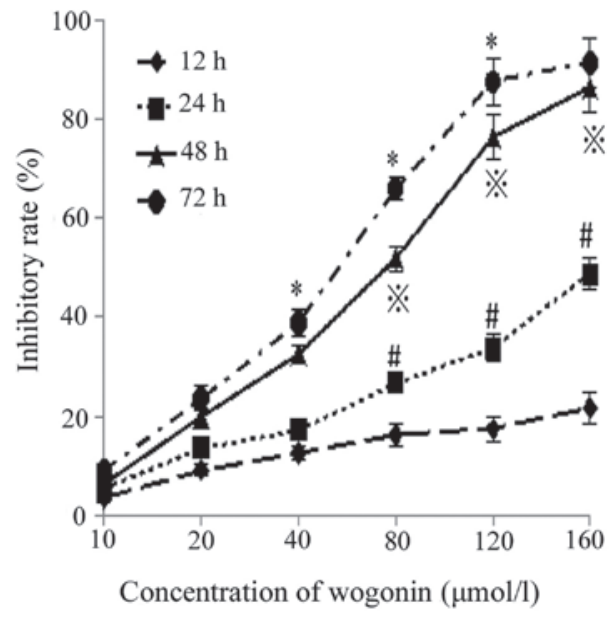

Figure 1. Wogonin inhibits the proliferation rate of SKM-1 cells in a timeand concentration-dependent manner. The inhibitory effect of wogonin on the SKM-1 cells was determined for the various time points following treatment using an MTT assay. \#,,, $\mathrm{P}<0.05$, compared with the control. ${ }^{*},{ }^{2} \mathrm{P}<0.05$ compared with the intergroup-paired group at the matched treatment.

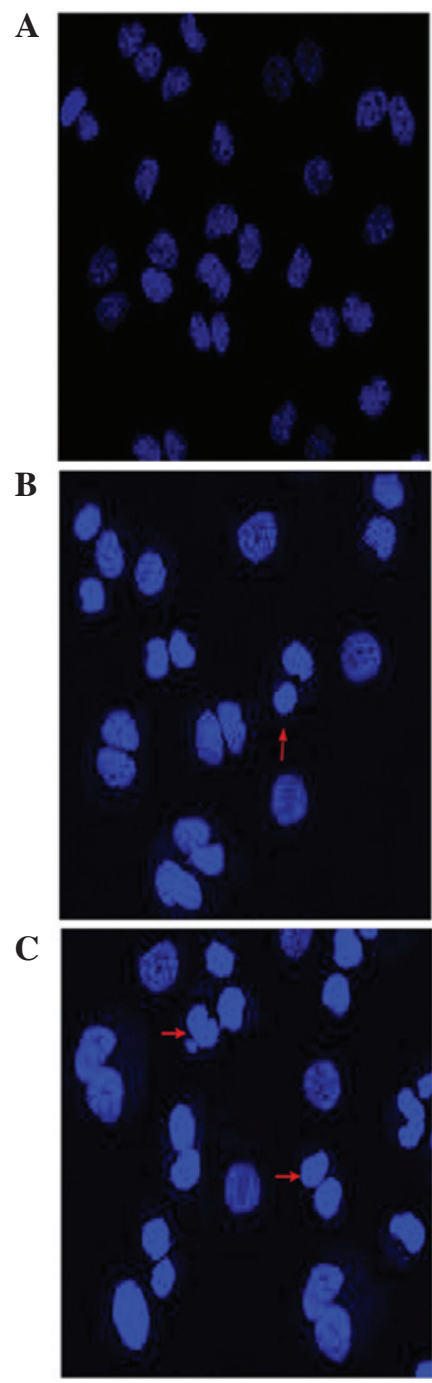

Figure 2. Nuclear morphological changes are observed in the SKM-1 cells following treatment with wogonin for $24 \mathrm{~h}$. Images of the cells were captured following (A) no treatment or treatment with (B) 40 or (C) $80 \mu \mathrm{mol} / 1$ wogonin, as observed under a fluorescence microscope (magnification, $\mathrm{x} 400$ ). The red arrows indicate the darker blue staining taken up by the cells containing condensed and fragmented DNA, which were undergoing apoptosis. 

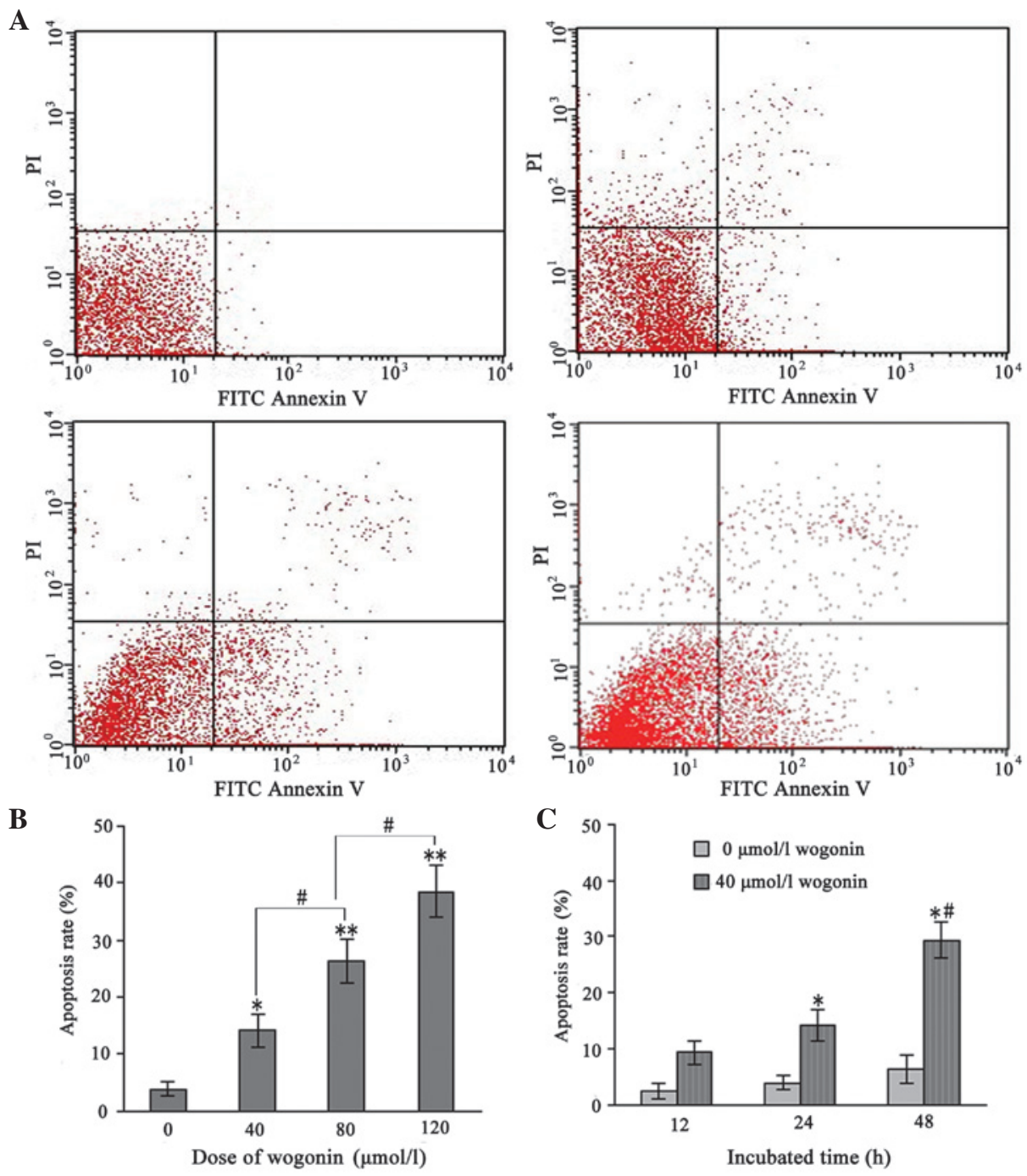

Figure 3. Treatment with wogonin increases the rate of apoptosis in a time- and concentration-dependent manner. The apoptotic rate of the SKM-1 cells treated with various concentrations of wogonin for (A and B) $24 \mathrm{~h}$, or $(\mathrm{C})$ with $40 \mu \mathrm{mol} / 1$ wogonin for the various durations. ${ }^{*} \mathrm{P}<0.05$; ${ }^{* *} \mathrm{P}<0.01$, compared with the control group at the matched treatment; ${ }^{\prime} \mathrm{P}<0.05$, compared with the intergroup-paired group at the matched treatment. FITC, fluorescein isothiocyanate; PI, propidium iodide.

of PARP. A significant difference was observed between them $(\mathrm{P}<0.05$; data not shown). Notably, the dose at which wogonin affected the expression of the apoptosis-associated proteins was similar to that at which the cell proliferation was suppressed and apoptosis was induced. Therefore, these results clearly suggested that the growth-inhibitory effects of wogonin on the SKM-1 cells were mediated by cell apoptosis.

\section{Discussion}

Chinese herbal medicines have been used for thousands of years in China and are increasingly being recognized as novel remedies for enhancing the efficacy, or alleviating the adverse effects, of tumor therapies (19). An accumulating body of evidence has demonstrated that wogonin induces cell death via cell cycle arrest and the induction of apoptosis in numerous types of human cancer cell lines (9), however, information on wogonin-induced apoptosis in human MDS cells is lacking. To provide an improved understanding of the mechanism underlying its anticancer activity, the effect of wogonin on human MDS cells was investigated in the present study.
The induction of apoptosis in cancer cells is one of the most important and direct ways to control the development of cancer and to eliminate tumors. An imbalance between proliferation and apoptosis may lead to unlimited cell proliferation, which may result in tumor development (20). Therefore, the effects of wogonin in antagonizing the proliferation of SKM-1 cells and cell apoptosis were initially investigated in the present study using MTT and annexin V-PI double-staining assays. The results demonstrated that wogonin significantly inhibited the proliferation of SKM-1 cells, in a time- and dose-dependent manner (Fig. 1). Furthermore, the present study also confirmed that wogonin suppressed cell proliferation, predominantly as a result of the induction of apoptosis, as demonstrated by the percentage of annexin $\mathrm{V}$-positive cells that were present and the characteristic morphological changes associated with apoptosis in the nucleus. As shown in Fig. 2, the nuclear morphological analysis revealed a dose-associated increase in the fraction of apoptotic cells with condensed and fragmented nuclei, as indicated by the darker blue fluorescence exhibited in wogonin-treated SKM-1 cells (Fig. 2A and B) compared with those cells with pale blue fluorescence in the control 


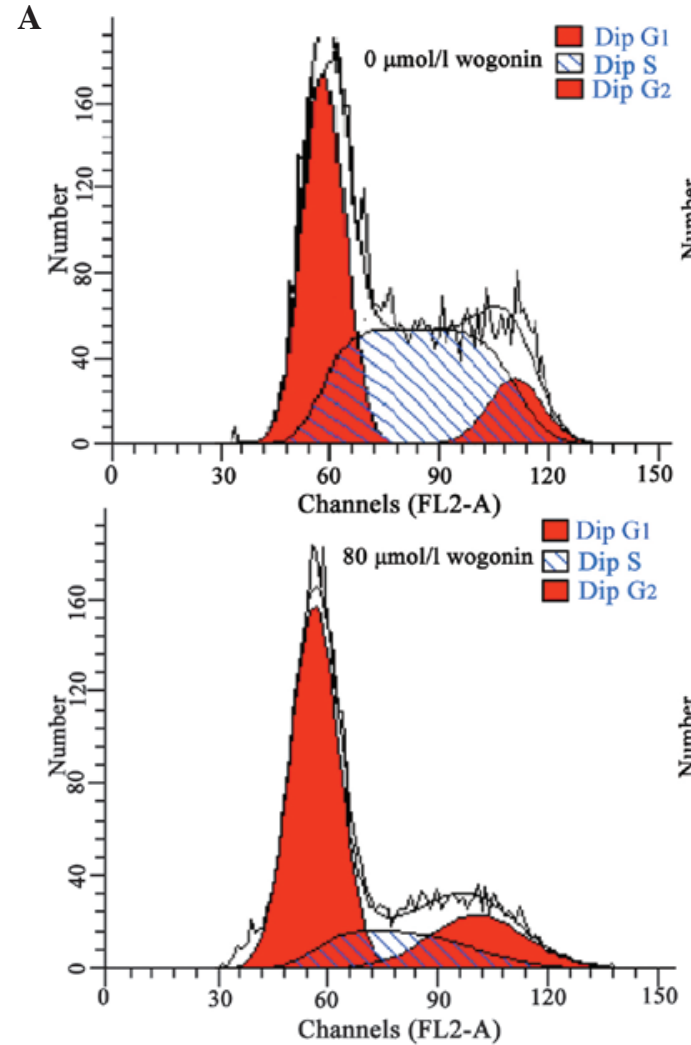

B

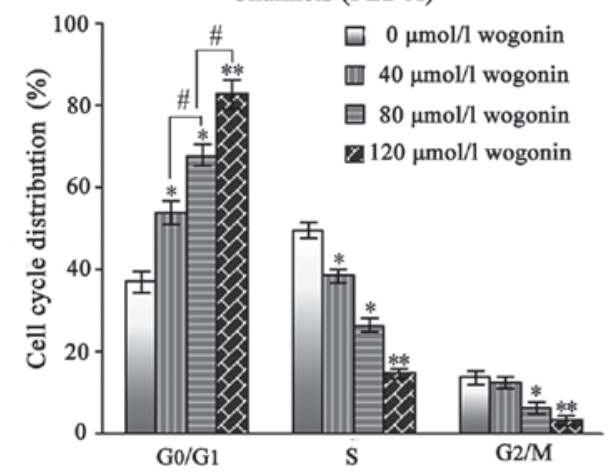

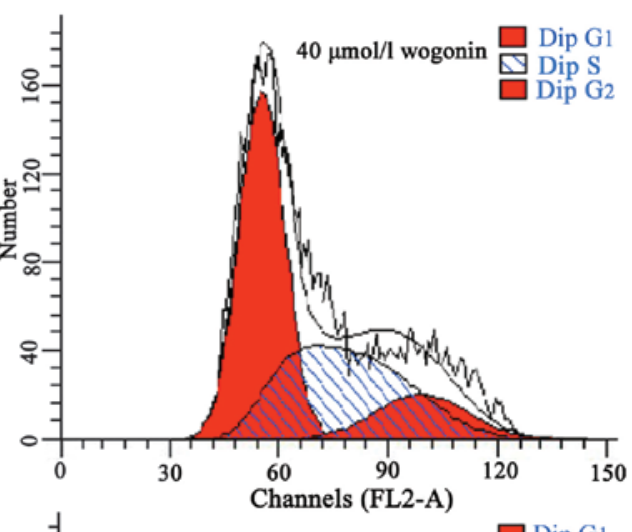

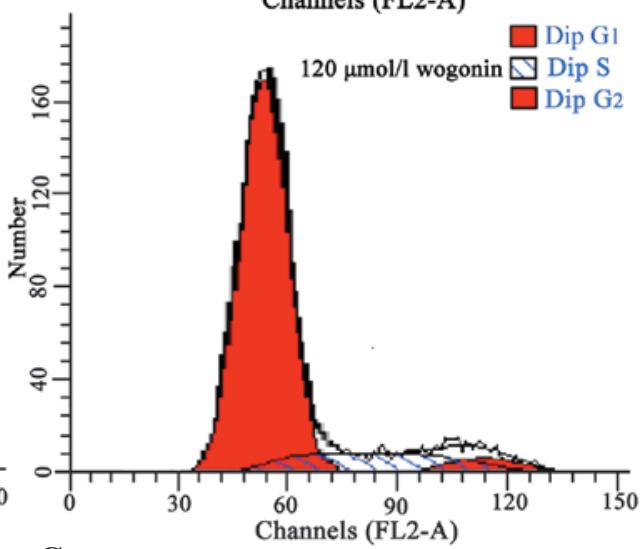

C

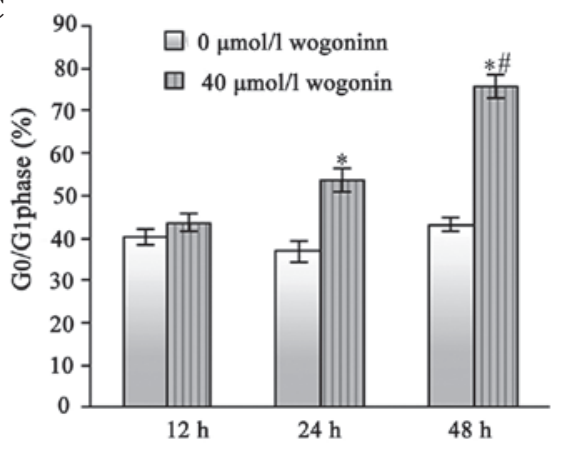

Figure 4. Cell cycle distributions and the percentages of cells in the $\mathrm{G}_{0} / \mathrm{G}_{1}$ phase. (A and B) The SKM-1 cells were treated with various concentrations of wogonin $(0,40,80$ or $120 \mu \mathrm{mol} / 1)$ for $24 \mathrm{~h}$, or (C) with $40 \mu \mathrm{mol} / 1$ wogonin for the various durations, as indicated. * $\mathrm{P}<0.05$ and ${ }^{* *} \mathrm{P}<0.01$, compared with the control group at the matched treatment; ${ }^{\#} \mathrm{P}<0.05$, compared with the intergroup-paired group at the matched treatment.

group (Fig. 2C), as observed with DAPI staining. Previously, it was reported that treatment with wogonin induces apoptosis and inhibits cell proliferation in other diseases of the hematopoietic system, including myeloma and B-cell non-Hodgkin's lymphoma cell lines $(21,22)$. This is consistent with the results of the present study and these findings clearly demonstrated that wogonin exerts anticancer effects through the induction of cell apoptosis.

Apoptosis results as a consequence of a series of precisely regulated events, which are frequently altered in tumor cells, and the apoptotic process is tightly regulated by a fine-tuned balance between proapoptotic and antiapoptotic factors. Various dysfunctions of the apoptotic pathway and uncontrolled cellular proliferation ultimately lead to carcinogenesis and tumor progression (23). In general, apoptotic cell death may be executed by the key molecular mechanism, involving mitochondria (the intrinsic pathway) and the death receptor pathways (the extrinsic pathway) (24). In each pathway, an apoptotic stimulus results in the activation of caspases either directly, or via the activation of the mitochondrial death program (25). Therefore, the expression levels of certain key apoptotic proteins, including caspases-3 and -9, Bax, Bcl-2, PARP and c-PARP, were assessed to determine the possible mechanism of wogonin-induced apoptosis. The Bcl-2 family of proteins (antiapoptotic proteins, including Bcl-2 and Bcl-xl, and proapoptotic proteins, including Bax and Bad), exert an important role in the apoptosis of cancer cells, since the interactions among these proteins set the threshold for cell survival $(26,27)$. In the present study, the results of the western blot analyses revealed that wogonin increased the expression of the proapoptotic protein, Bax, in the SKM-1 cells following treatment for $48 \mathrm{~h}$, whereas it led to a decrease in the expression of the antiapoptotic protein, $\mathrm{Bcl}-2$, thereby resulting in an increase in the ratio of proapoptotic to antiapoptotic Bcl-2 family proteins, in favor of apoptosis in the MDS cells. It was reported that the induction of mitochondrial apoptosis 


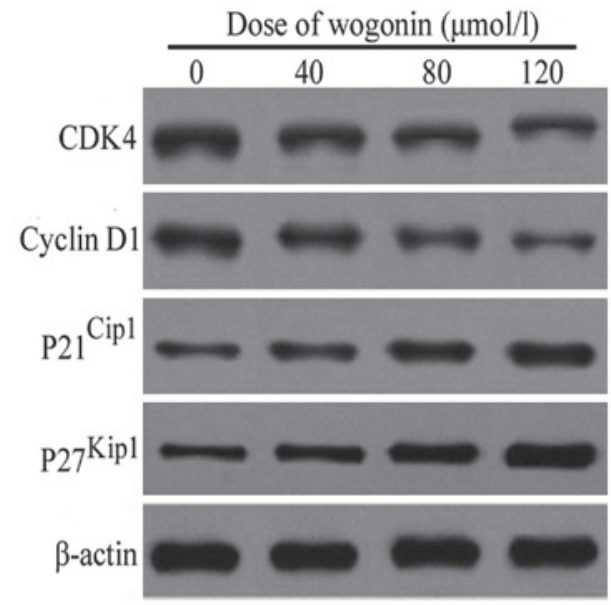

Figure 5. Cell-cycle regulatory proteins in the SKM-1 cells following treatment with wogonin for $48 \mathrm{~h}$, as determined by western blot analysis. $\beta$-actin was used as the protein loading control. CDK, cyclin-dependent kinase.

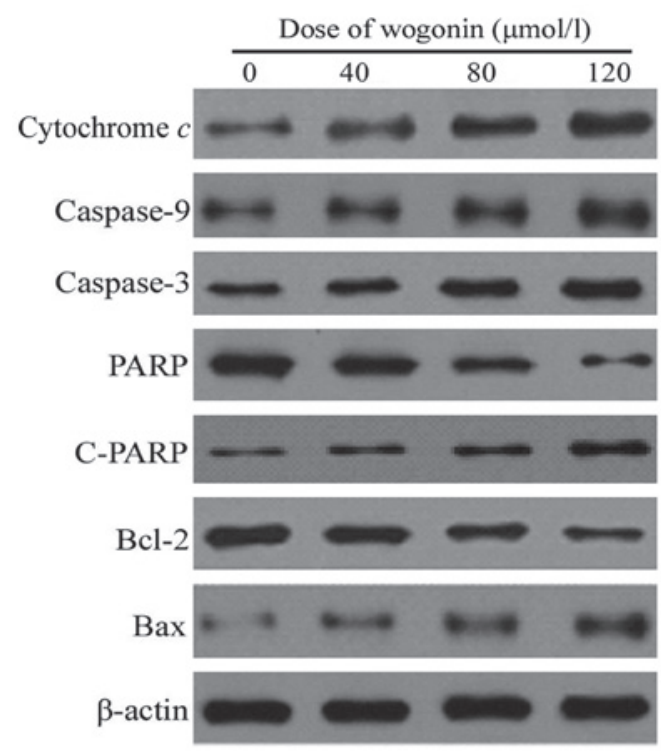

Figure 6. Apoptosis-associated proteins in SKM-1 cells following treatment with wogonin for $48 \mathrm{~h}$, as determined by western blot analysis. $\beta$-actin was used as a protein loading control. PARP, poly(ADP-ribose) polymerase; C-PARP, cleaved PARP.

requires the involvement of the Bcl-2 protein family (21), in which Bax and $\mathrm{Bcl}-2$ are key proteins involved in the regulation of the mitochondrial pathway. The predominant mechanism by which Bcl-2 family members initiate or prevent apoptosis is by controlling the release of cytochrome $c$ and other proapoptotic factors from the mitochondria (28-30). During this process, cytosolic cytochrome $c$ activates procaspase- 9 by binding to apoptotic protease-activating factor 1 in the presence of dATP, leading to the activation of caspase-9 (31). Subsequently, downstream effector caspases, including caspase-3, are activated, which eventually trigger apoptosis $(32,33)$. The present study provided evidence to suggest that wogonin increased the expression of cytochrome $c$ and activated (cleaved) caspases-3 and -9 in SKM-1 cells following treatment for $48 \mathrm{~h}$. The caspase signaling pathway, which is activated extrinsically and intrinsically, is the major mechanism of apoptosis in most cellular systems (34). Notably, the present study identified that the increase in apoptosis mediated by wogonin was accompanied by a decreased level of PARP and the emergence of c-PARP, and markedly increased levels of Bax protein with concomitantly decreased levels of Bcl-2. An accumulating body of evidence has identified that PARP is one component of the caspase-mediated pathway of apoptosis, and c-PARP is considered to be a marker of apoptosis, being critically involved in the intrinsic apoptosis pathway (35-38). It has long been known that wogonin exerts apoptosis-inducing effects in malignant cells by changing the mitochondrial membrane potential $(36,38)$. The crucial step in the mitochondrial apoptotic pathway is the loss of the mitochondrial membrane potential, triggering the activation of the apoptotic cascade and the execution of cell death (39). The wogonin-induced decreased ratio of $\mathrm{Bcl}-2$ to $\mathrm{Bax}$, and increased expression of cleaved caspases-3 and -9 , was demonstrated in human breast cancer cells and in vascular smooth muscle cells $(4,40)$. Therefore, it is reasonable to hypothesize that wogonin-induced apoptosis of the MDS cells is mediated by the mitochondrial pathway through modulating the ratio of Bcl-2 to Bax.

Cell growth is tightly regulated by cell-cycle checkpoints and apoptosis is often associated with $\mathrm{G}_{1}$ phase arrest of the cell cycle (41). In the present study, the cell cycle analysis by FCM revealed that wogonin induced $a \mathrm{G}_{0} / \mathrm{G}_{1}$ cell-cycle arrest of the SKM-1 cells in a dose-and a time-dependent manner. Evidence in the literature suggests that wogonin may induce the $G_{1}$ phase arrest of cells associated with several human malignancies, including non-Hodgkin's lymphoma Raji (22), leukemia U-937 (42), human colorectal cancer carcinoma (43) and human cervical carcinoma HeLa (9) cells. All these reports suggested that one of the mechanisms by which wogonin may act to inhibit the proliferation of cancer cells is through an inhibition of cell cycle progression. It is well documented that cell cycle progression is partly controlled by a family of protein kinase complexes in eukaryotic cells, including CDKs and their activating partners, the cyclins (44-47). During the $\mathrm{G}_{0} / \mathrm{G}_{1}$ phase progression, cyclin D1 binds to CDK4/CDK6, resulting in the formation of the cyclin E/CDK4 complex, eventually driving the cell from $\mathrm{G}_{1}$ to $\mathrm{S}$ phase (48). In the present study, it was revealed that treatment of the SKM-1 cells with wogonin markedly decreased the expression of cyclin D1 and its upstream kinase, CDK4, in a dose-dependent manner. It is noteworthy that the exposure of different cancer cell lines to wogonin was previously shown to reduce the protein levels of cyclin $\mathrm{D}$, resulting in growth inhibition at the $G_{0} / G_{1}$ phase (5). Therefore, it is possible that the antiproliferative effects of wogonin are due to the inhibition of cyclin D1 expression in MDS cells. The cell cycle progression in eukaryotic cells is also regulated by the relative balance between the cellular concentrations of CDK inhibitors, including the $\mathrm{p} 21^{\mathrm{Cip} 1}$ and $\mathrm{p} 27^{\mathrm{Kipl}}$ proteins of the Cip/Kip family (49). Furthermore, the overexpression of $\mathrm{p} 27^{\mathrm{Kip} 1}$ was revealed to prevent the activation of CDKs and entry into the S-transition phase (50), and $\mathrm{p} 21^{\mathrm{Cip1}}$ was demonstrated to exert an important role in regulating the $\mathrm{G}_{1}-\mathrm{S}$ and $\mathrm{G}_{2}$ checkpoints (51). The present study revealed that a marked increase in the protein expression levels of $\mathrm{p} 27^{\mathrm{Kip} 1}$ and $\mathrm{p} 21^{\mathrm{Cip} 1}$ in the SKM-1 cells was observed following treatment with wogonin for $48 \mathrm{~h}$. Taken together, these data suggested that wogonin induced $\mathrm{G}_{0} / \mathrm{G}_{1}$ phase arrest in the MDS cells by modulating several key $\mathrm{G}_{1}$ regulatory proteins, 
including CDK4 and cyclin D1, in addition to upregulating the expression of $\mathrm{p} 27^{\mathrm{Kip} 1}$ and $\mathrm{p} 21^{\text {Cip1 }}$.

In conclusion, the present study provided evidence that wogonin acted on several regulatory factors (cyclin D1, CDK4, p2 $21^{\text {Cip1 }}$ and $\mathrm{p} 27^{\mathrm{Kip} 1}$ ), causing a $\mathrm{G}_{0} / \mathrm{G}_{1}$ phase arrest, halting cell cycle progression, and inducing apoptosis in the MDS cells, which may be mediated by the mitochondrial pathway through a modulation of the ratio of Bcl-2 to Bax. Therefore, the findings in the present study revealed that wogonin may be a putative target for therapeutic action in the treatment of MDS. However, further studies,including exploring the effects of long-term in vivo exposure to wogonin, are required.

\section{Acknowledgements}

This study was supported by the National Nature Science Foundation of People's Republic China (no. 81372985) and the National Nature Science Foundation of People's Republic China (no. 81200877).

\section{References}

1. Chen Y, Liu K, Xu L, Chen H, Liu D, Zhang X, Shi H, Han W, Wang Y, Zhao T, et al: HLA-mismatched hematopoietic SCT without in vitro T-cell depletion for myelodysplastic syndrome. Bone Marrow Transplant 45: 1333-1339, 2010.

2. Kindwall-Keller T and Isola LM: The evolution of hematopoietic SCT in myelodysplastic syndrome. Bone Marrow Transplant 43 : 597-609, 2009.

3. Polier G, Ding J, Konkimalla BV, Eick D, Ribeiro N, Köhler R, Giaisi M, Efferth T, Desaubry L, Krammer PH and Li-Weber M: Wogonin and related natural flavones are inhibitors of CDK9 that induce apoptosis in cancer cells by transcriptional suppression of Mcl-1. Cell Death Dis 2: e182, 2011.

4. Chung HY, Jung YM, Shin DH, Lee JY, Oh MY, Kim HJ, Jang KS, Jeon SJ, Son KH and Kong G: Anticancer effects of wogonin in both estrogen receptor-positive and -negative human breast cancer cell lines in vitro and in nude mice xenografts. Int J Cancer 122: 816-822, 2008.

5. Li-Weber M: New therapeutic aspects of flavones: The anticancer properties of Scutellaria and its main active constituents Wogonin, Baicalein and Baicalin. Cancer Treat Rev 35: 57-68, 2009.

6. Baumann S, Fas SC, Giaisi M, Müller WW, Merling A, Gülow K, Edler L, Krammer PH and Li-Weber M: Wogonin preferentially kills malignant lymphocytes and suppresses T-cell tumor growth by inducing PLCgammal-and $\mathrm{Ca}^{2+}$-dependent apoptosis. Blood 111: 2354-2363, 2008

7. Chow SE, Chang YL, Chuang SF and Wang JS: Wogonin induced apoptosis in human nasopharyngeal carcinoma cells by targeting GSK- $3 \beta$ and $\Delta$ Np63. Cancer Chemother Pharmacol 68: 835-845, 2011.

8. Lin CC, Kuo CL, Lee MH, Lai KC, Lin JP, Yang JS, Yu CS, Lu CC, Chiang JH, Chueh FS and Chung JG: Wogonin triggers apoptosis in human osteosarcoma U-2 OS cells through the endoplasmic reticulum stress, mitochondrial dysfunction and caspase-3-dependent signaling pathways. Int J Oncol 39: 217-224, 2011.

9. Yang L, Zhang HW, Hu R, Yang Y, Qi Q, Lu N, Liu W, Chu YY, You QD and Guo QL: Wogonin induces G(1) phase arrest through inhibiting Cdk4 and cyclin D1 concomitant with an elevation in p21Cip1 in human cervical carcinoma HeLa cells. Biochem Cell Biol 87: 933-942, 2009.

10. Lu N, Gao Y, Ling Y, Chen Y, Yang Y, Gu HY, Qi Q, Liu W, Wang XT, You QD and Guo QL: Wogonin suppresses tumor growth in vivo and VEGF-induced angiogenesis through inhibiting tyrosine phosphorylation of VEGFR2. Life Sci 82: 956-963, 2008.

11. Kelloff GJ, Crowell JA, Steele VE, Lubet RA, Malone WA, Boone CW, Kopelovich L, Hawk ET, Lieberman R, Lawrence JA, et al: Progress in cancer chemoprevention: Development of diet-derived chemopreventive agents. J Nutr 130 (2 Suppl): S467-S471, 2000.
12. Cheng YL, Lee SC, Lin SZ, Chang WL, Chen YL, Tsai NM, Liu YC, Tzao C, Yu DS and Harn HJ: Anti-proliferative A549 human activity of Bupleurum scrozonerifolium in lung cancer cells in vitro and in vivo. Cancer Lett 222: 183-193, 2005.

13. Trivedi PP, Roberts PC, Wolf NA and Swanborg RH: NK cells inhibit $\mathrm{T}$ cell proliferation via p21-mediated cell cycle arrest. J Immunol 174: 4590-4597, 2005.

14. Canavese M, Santo L and Raje N: Cyclin dependent kinases in cancer: Potential for therapeutic intervention. Cancer Biol Ther 13: 451-457, 2012.

15. Vermeulen K, Van Bockstaele DR and Berneman ZN: The cell cycle: A review of regulation, deregulation and therapeutic targets in cancer. Cell Prolif 36: 131-149, 2003.

16. Nakagawa T, Matozaki S, Murayama T, Nishimura R, Tsutsumi M, Kawaguchi R, Yokoyama Y, Hikiji K, Isobe T and Chihara K: Establishment of a leukaemic cell line from a patient with acquisition of chromosomal abnormalities during disease progression in myelodysplastic syndrome. Br J Haematol 85: 469-476, 1993.

17. Xia G, Chen B, Ding J, Gao C, Lu H, Shao Z, Gao F and Wang X: Effect of magnetic $\mathrm{Fe}_{3} \mathrm{O}_{4}$ nanoparticles with 2-methoxyestradiol on the cell-cycle progression and apoptosis of myelodysplastic syndrome cells. Int J Nanomedicine 6: 1921-1927, 2011.

18. Jiang Z, Chen BA, Xia GH, Wu Q, Zhang Y, Hong TY, Zhang W, Cheng J, Gao F, Liu LJ, et al: The reversal effect of magnetic $\mathrm{Fe} 3 \mathrm{O} 4$ nanoparticles loaded with cisplatin on SKOV3/DDP ovarian carcinoma cells. Int J Nanomedicine 4: 107-114, 2009.

19. Surh YJ: Cancer chemoprevention with dietary phytochemicals. Nat Rev Cancer 3: 768-780, 2003.

20. Karunagaran D, Joseph J and Kumar TR: Cell growth regulation. Adv Exp Med Biol 595: 245-268, 2007.

21. Zhang M, Liu LP, Chen Y, Tian XY, Qin J, Wang D, Li Z and Mo SL: Wogonin induces apoptosis in RPMI 8226, a human myeloma cell line, by downregulating phospho-Akt and overexpressing Bax. Life Sci 92: 55-62, 2013.

22. Wang L, Zhang H, Chen B, Xia G, Wang S, Cheng J, Shao Z, Gao C, Bao W, Tian L, et al: Effect of magnetic nanoparticles on apoptosis and cell cycle induced by wogonin in Raji cells. Int J Nanomedicine 7: 789-798, 2012.

23. Elmore S: Apoptosis: A review of programmed cell death. Toxicol Pathol 35: 495-516, 2007.

24. Hengartner MO: The biochemistry of apoptosis. Nature 407: 770-776, 2000

25. Chen B, Liang Y, Wu W, Cheng J, Xia G, Gao F, Ding J, Gao C, Shao Z, Li G, et al: Synergistic effect of magnetic nanoparticles of $\mathrm{Fe}_{3} \mathrm{O}_{4}$ with gambogic acid on apoptosis of K562 leukemia cells. Int J Nanomedicine 4: 251-259, 2009.

26. Cotter TG: Apoptosis and cancer: The genesis of a research field. Nat Rev Cancer 9: 501-507, 2009.

27. Leber B, Lin J and Andrews DW: Still embedded together binding to membranes regulates $\mathrm{Bcl}-2$ protein interactions. Oncogene 29: 5221-5230, 2010

28. Youle RJ and Strasser A: The BCL-2 protein family: Opposing activities that mediate cell death. Nat Rev Mol Cell Biol 9: 47-59, 2008.

29. Kroemer G and Reed JC: Mitochondrial control of cell death. Nat Med 6: 513-519, 2000.

30. Wei MC, Zong WX, Cheng EH, Lindsten T, Panoutsakopoulou V, Ross AJ, Roth KA, MacGregor GR, Thompson CB, Korsmeyer SJ, et al: Proapoptotic BAX and BAK: A requisite gateway to mitochondrial dysfunction and death. Science 292: 727-730, 2001.

31. Sanchez-Alczar JA, Khodjakov A and Schneider E: Anticancer drugs induce increased mitochondrial cytochrome $c$ expression that precedes cell death. Cancer Res 61: 1038-1044, 2001.

32. Riedl SJ and Salvesen GS: The apoptosome: Signaling platform of cell death. Nat Rev Mol Cell Biol 8: 405-413, 2007.

33. Caserta TM, Smith AN, Gultice AD, Reedy MA and Brown TL: Q-VD-OPh, a broad spectrum caspase inhibitor with potent antiapoptotic properties. Apoptosis 8: 345-352, 2003.

34. Fadeel B and Orrenius S: Apoptosis: A basic biological phenomenon with wide-ranging implications in human disease. J Intern Med 258: 479-517, 2005.

35. Agarwal A, Mahfouz RZ, Sharma RK, Sarkar O, Mangrola D and Mathur PP: Potential biological role of poly (ADP-ribose) polymerase (PARP) in male gametes. Reprod Biol Endocrinol 7: 143,2009

36. Danial NN: BCL-2 family proteins: Critical checkpoints of apoptotic cell death. Clin Cancer Res 13: 7254-7263, 2007.

37. Mahfouz RZ, Said TM, Mangrola D, et al: Potential roles of poly (ADP-ribose) polymerase in male reproduction. Arch Med Sci 5: S92-S98, 2009. 
38. Zhang PX, Li HM, Chen D, Ni J, Kang Y and Wang S: Oleanolic acid induces apoptosis in human leukemia cells through caspase activation and poly (ADP-ribose) polymerase cleavage. Acta Biochim Biophys Sin (Shanghai) 39: 803-809, 2007.

39. Kroemer G, Galluzzi L and Brenner C: Mitochondrial membrane permeabilization in cell death. Physiol Rev 87: 99-163, 2007.

40. Liu YM, Wang X, Nawaz A, Kong ZH, Hong Y, Wang CH and Zhang JJ: Wogonin ameliorates lipotoxicity-induced apoptosis of cultured vascular smooth muscle cells via interfering with DAG-PKC pathway. Acta Pharmacol Sin 32: 1475-1482, 2011.

41. Liu Q, Hilsenbeck S and Gazitt Y: Arsenic trioxide-induced apoptosis in myeloma cells: p53-dependent G1 or G2/M cell cycle arrest, activation of caspase- 8 or caspase- 9 , and synergy with APO2/TRAIL. Blood 101: 4078-4087, 2003.

42. Zhang HW, Yang Y, Zhang K, Qiang L, Yang L, Yang L, Hu Y, Wang XT, You QD and Guo QL: Wogonin induced differentiation and G1 phase arrest of human U-937 leukemia cells via PKC delta phosphorylation. Eur J Pharmacol 591: 7-12, 2008.

43. He L, Lu N, Dai Q, Zhao Y, Zhao L, Wang H, Li Z, You Q and Guo Q: Wogonin induced G1 cell cycle arrest by regulating Wnt/3-catenin signaling pathway and inactivating CDK8 in human colorectal cancer carcinoma cells. Toxicology 312: 36-47, 2013.
44. Malumbres M and Barbacid M: Mammalian cyclin-dependent kinases. Trends Biochem Sci 30: 630-641, 2005.

45. Paulovich AG and Hartwell LH: A checkpoint regulates the rate of progression through $\mathrm{S}$ phase in S. cerevisiae in response to DNA damage. Cell 82: 841-847, 1995.

46. Walker JL and Assoian RK: Integrin-dependent signal trans,duction regulating cyclin D1 expression and G1 phase cell cycle progression. Cancer Metastasis Rev 24: 383-393, 2005.

47. Lew DJ and Kornbluth S: Regulatory roles of cyclin dependent kinase phosphorylation in cell cycle control. Curr Opin Cell Biol 8: 795-804, 1996

48. Harbour JW and Dean DC: Rb function in cell-cycle regulation and apoptosis. Nat Cell Biol 2: E65-E67, 2000.

49. Schwartz GK and Shah MA: Targeting the cell cycle: A new approach to cancer therapy. J Clin Oncol 23: 9408-9421, 2005

50. Abukhdeir AM and Park BH: P21 and p27: Roles in carcinogenesis and drug resistance. Expert Rev Mol Med 10: e19, 2008.

51. Gartel AL and Tyner AL: The role of the cyclin-dependent kinase inhibitor p21 in apoptosis. Mol Cancer Ther 1: 639-649, 2002. 